\title{
Retail network planning - Achieving competitive advantage through geographical analysis
}

Received (in revised form): 7th February, 2005

\section{Andy Thompson}

is Founding Director of GeoBusiness Solutions Ltd, a specialist geographical analysis and locational modelling firm, with a range of clients in retail, leisure, financial services, property and the public sector. He was formerly a manager within Rank Leisure's Site Analysis Department.

\section{Jonathan Walker}

is a co-founder of GeoBusiness Solutions Ltd. He has also worked as a manager at Rank Leisure's Site Analysis Department.

\begin{abstract}
Retail businesses have long recognised that understanding and improving overall performance starts with analysis at the micro or local market level. Attention has been focused on an increasing body of evidence that demonstrates market share can vary significantly from one local market to another. Added to this realisation, there is often a pressing need to provide high-quality information to support new site development, outlet closures and mergers, where the location of customers and competitor outlets plays a crucial role in determining the outcome of decisions. Using the right tools and techniques, it is possible to predict these outcomes with increasing levels of reliability.
\end{abstract}

Jonathan Walker

GeoBusiness Solutions Ltd, 1 Holly Court, Tring Road, Wendover, Bucks, HP22 6PE, UK.

Tel: +44 (0)1296 622555; Fax: +44 (0)1296 622118; e-mail: jon@geobusiness.co.uk

\section{INTRODUCTION}

Understanding and improving overall performance has led to an intensifying of interest in geographical analysis techniques, analysis tools such as Geographical Information Systems (GIS) and, more specifically, the geographical data which organisations can draw upon to build a detailed picture of retail market performance at fine levels of geography.

Today, competitive advantage is not so much determined by the having or not-having of a geographical analysis capability, but by the quality of the models and analysis developed and, more importantly, the way in which these tools are used to support business decisions. Examples of applications of geographical analysis in retail network strategies are shown in Table 1.

\section{DECISION SUPPORT REQUIREMENTS}

Developing a geographical analysis capability is clearly not an aim in itself, and while it is necessary that users and developers have certain technical competencies, it is important that the usage and direction of geographical analysis within an organisation is driven by business needs and is not seen as the realm of technical experts.

A good starting point is to define a series of questions that the business is trying to address. This provides guidelines to those reviewing the 
Table 1: Applications of geographical analysis in retail network strategies

\begin{tabular}{|c|c|}
\hline Market & Example uses \\
\hline Retail & $\begin{array}{l}\text { New store sales forecasts } \\
\text { Impact analysis } \\
\text { Store performance analysis }\end{array}$ \\
\hline Leisure & $\begin{array}{l}\text { Loyalty card/customer database analysis } \\
\text { Demand elasticity } \\
\text { Local marketing } \\
\text { Site development } \\
\text { Support for licensing }\end{array}$ \\
\hline Finance & $\begin{array}{l}\text { Local market channel strategy } \\
\text { Optimal networks } \\
\text { Service planning } \\
\text { Merger impact analysis } \\
\text { Optimal ATM networks }\end{array}$ \\
\hline Property & $\begin{array}{l}\text { Feasibility studies } \\
\text { Catchment analysis } \\
\text { Planning research }\end{array}$ \\
\hline Fast moving consumer goods (FMCG) & $\begin{array}{l}\text { Supply chain logistics } \\
\text { POS/channel management } \\
\text { Marketing campaign support }\end{array}$ \\
\hline Medical & $\begin{array}{l}\text { Sales territory planning } \\
\text { Service planning } \\
\text { Patient flows }\end{array}$ \\
\hline Motor manufacturing & $\begin{array}{l}\text { Dealer network planning } \\
\text { After sales forecasting }\end{array}$ \\
\hline Petrol retailing & $\begin{array}{l}\text { Sales analysis } \\
\text { Site development }\end{array}$ \\
\hline Media & $\begin{array}{l}\text { Local campaign planning } \\
\text { Media targeting } \\
\text { Outdoor advertising planning }\end{array}$ \\
\hline
\end{tabular}

capability and a benchmark against which the solution can be judged. Crucially, for the decision makers it goes some way to quantifying the benefits that can be expected:

- what will happen if outlet $\mathrm{A}$ in centre $\mathrm{B}$ is closed;

- what the result of refurbishing the outlet network in region $\mathrm{X}$ will be;

- what the effect of competitors $\mathrm{C}$ and D merging will be;

- why market share is below average in certain localities;

- how actual performance compares with expected performance given the level of competition and local market size;
- what mix of distribution channels will be most efficient in each sales territory?

\section{ACHIEVING COMPETITIVE ADVANTAGE}

Building a geographical analysis capability and profitable decisionsupport solution requires the bringing together of a number of components. Externally available data and software provide the foundations upon which a solution can be built but offer little in terms of competitive advantage.

The solution should include the organisation's own customer and business data, models which turn data 


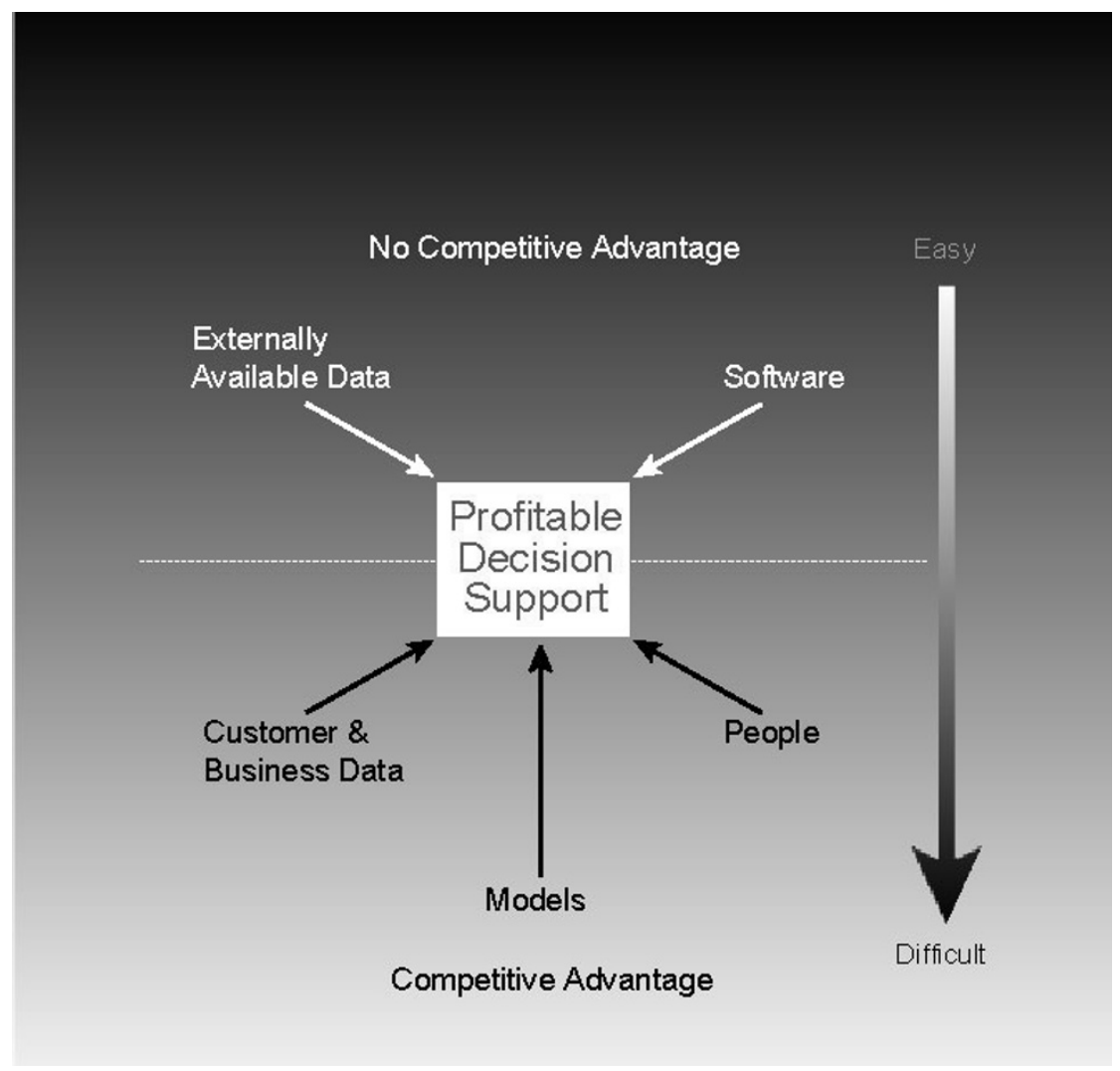

Figure 1 External data and software alone do not provide competitive advantage

into market forecasts and people who will operate the system, analyse the outputs and make decisions based on the information provided.

\section{External data}

Data are a key input for any geographical analysis and great care must be taken when evaluating and selecting the most suitable data sets for particular business needs. Considerations include how the data are going to be used, the need to integrate with other data sets, and any 'cost versus quality' considerations.

\section{Zone boundary data}

Boundary data will be the basic building block of any analysis or modelling and therefore need careful consideration.
These zones will subdivide the territory to be analysed (region, country or countries) into a number of smaller geographic areas and allocate consumer demand for products to these individual zones. The number of zones will be dependent on the availability of other data for spatial aggregation or disaggregation and also the level of accuracy required for the analysis. Examples of zone boundaries are census areas, local government areas, postcode (zipcode) areas and it is a general rule of thumb that cost of the data will increase with the increase in accuracy and coverage of the data.

\section{Census data}

Census data remain the most comprehensive source of data on 
population size and characteristics by small geographical area. Completion of a census return is mandatory and hence coverage is almost 100 per cent.

The level of detail provided by the census is far greater than would ever be required for market analysis and usually a small aggregated subset of the full census is used.

The release of the 2001 census in the UK represented a landmark in this respect, as the data are now available free from government, although one should not underestimate the cost of acquiring and assembling the data in an analysis-ready format.

\section{Population estimates and projections}

To address recency issues with the census, various models have been applied, both to update the population to more recent times and to project forward into future years. These take into account ageing, births, deaths and population movements and are important in helping businesses assess future demand and plan their future supply networks accordingly.

\section{Geodemographic classifications}

Geodemographic classifications classify small areas according to the salient characteristics of their residents - usually from census data. The main product differentiator is the number and type of input variables and while there is an ongoing debate among suppliers as to which products are superior, in reality they tend to share the same strengths and weaknesses.

\section{Lifestyle data}

Lifestyle data can offer a useful supplement to the census or geodemographic classifications. The data are derived from questionnaires completed on a voluntary basis. Respondents are targeted to complete survey updates allowing significant databases to be built up over time. These surveys have now reached critical mass in terms of the number of respondents and can provide statistically valid samples upon which residential demand models can be built.

\section{Propensity data}

Propensity data provide a means for converting the characteristics and size of the population into estimates of patronage levels or spending power. Reports and market research findings often provide a rich source of information for calculating propensity.

These are applied to the population in each residential (or workplace) zone to estimate overall market size. In essence, this provides a 'bottom-up' method of calculating market size as the estimates of consumption by small area can all be added together to estimate the size of the macro market.

Any market size estimates should always be constrained by an independent market size taken from a different source. For instance, it is possible to estimate from population characteristics the readership of any newspaper using market research by household characteristics. The extent to which the resulting estimates at small area level are plausible can be demonstrated by comparing the sum of all these low-level estimates with known national circulation figures.

\section{Contextual data}

Contextual data include, for example, the location of roads, motorways, railways and urban areas. These provide reference, or context, for the user of map output. 
For the purposes of analysis, contextual data are of limited value, however contextual data can improve the presentation quality of output to the extent that it can make the difference between the analysis being used or ignored.

\section{Competitor locations}

The majority of data sets discussed so far have concentrated on quantifying the size of the market. In order to begin to address questions of market share, it is important to amass quantitative information on competitor activity, especially the location, size and performance of competitor locations. The commercial availability of competitor databases varies greatly between retail markets. In the absence of such a source, it is incumbent upon the business to compile its own database, which may need to be built from a number of sources and supplemented with field research.

\section{Customer and business data}

Business data are any data which are held by an organisation on its own systems and is not generally available to competitors and thus represents a powerful source of competitive advantage.

The level of customer information available to an organisation is highly dependent upon the systems that are in place to capture customer activity.

For many retailers there is scant customer information available. In such circumstances, it is imperative to make the best possible use of the available data, to identify the minimal requirements and, if necessary, to undertake a data capture exercise.

Conversely, other retailers have captured customer information through store cards and customer loyalty schemes.
As such the problems of the 'data rich' and the 'data poor' are very different. Organisations with meagre customer data need to make best use of what they have by applying modelling techniques to simulate missing data. On the other hand, those businesses overwhelmed by vast quantities of data need first to integrate the data so that they can be analysed, and secondly to have the appropriate tools to make optimal use of the information 'hidden' in the data.

Other business data may include accounting information such as sales, admissions, operating costs and margins. It is crucial that these data are available for geographical analysis. Without them the analysis outputs are likely to provide a series of interesting facts and figures but little of significant value in supporting decisions.

\section{Software tools}

While purists would seek to draw a distinction between GIS and desktop mapping, for the purpose of retail market analysis, the key differences come down to price and ease of use. The GIS will provide a single environment in which all data sources can be integrated and analysed to produce the required results.

Most GIS systems will come as a relatively low-cost base system and then require the purchase of extensions or add-ons localised for the territory or retail market type. Examples of these add-ons include drivetime analysis tools and area analysis and reporting tools. A drivetime analysis package utilises a digital version of a road network to calculate travel time or distance from demand zones (customer locations) to stores (destinations). This analysis is used to determine distance decay effects and trip cost patterns for different store/customer profiles and is used as an input to modelling. 
Table 2: Comparison of modelling techniques

\begin{tabular}{llll}
\hline & Analogues & Regression & Gravity modelling \\
\hline Sales prediction & $\checkmark$ & $\checkmark \checkmark$ & $\checkmark \checkmark \checkmark$ \\
Impact analysis & N/A & N/A & $\checkmark \checkmark \checkmark$ \\
Market share analysis & N/A & N/A & $\checkmark \checkmark \checkmark$ \\
Network optimisation & N/A & N/A & $\checkmark \checkmark \checkmark$ \\
Implementation & Easy & Easy & Difficult \\
\hline
\end{tabular}

Area analysis tools facilitate the creation and storage of catchments, typically defined by radial distance, buffer, drivetime, drive distance or a user defined area. Standard or user defined reports can be run, which will relate to specific variables in preloaded data sets, eg census, retail expenditure estimates or numbers of customers.

Other tools employed in retail network analysis are statistical analysis packages and database management systems. Statistical analysis is used to examine the relationships between different data or data combinations, for example, to identify key variables that drive store attractiveness or stores sales by product. The main data repository will be a database management system or data warehouse. These systems will be used to examine and exploit information in the data and via the GIS tools provide an environment suitable for geographical analysis.

\section{Store forecasting models}

Models take the output provided by GIS queries and geodemographic data sets and convert these into predictions of key market performance indicators. Features of the different modelling techniques are compared in Table 2.

\section{Analogues}

Analogue models are used principally for estimating turnover for new outlets, as they work on the principle of similarity. By finding sites which are already trading and are similar in characteristics to a proposed unit, it follows that a good estimate of the likely performance of the new outlet will be the average of this subset.

Analogue models can often prove attractive, particularly because they are simple to implement and the logic easily understood by those involved in site evaluation.

Business users, however, should be aware of the potential drawbacks associated with analogue models:

- they are only a viable option where the organisation has a sufficiently large network of outlets from which to draw the analogue set;

- the influence of one rogue outlet can have a disproportionate effect on the model's predicted outcome;

- the technique cannot be applied when the organisation is developing new concepts or new store formats, where historical trading data are not available. This makes it an inappropriate technique for any organisation that is seeking to be innovative.

\section{Multiple regression}

Multiple regression and other statistical techniques seek to quantify the relationship between a set of variables and a single dependent variable, eg store sales. Multiple regression models remain popular owing to their low cost and simplicity, however a number of drawbacks have become apparent especially when compared to other available techniques. 


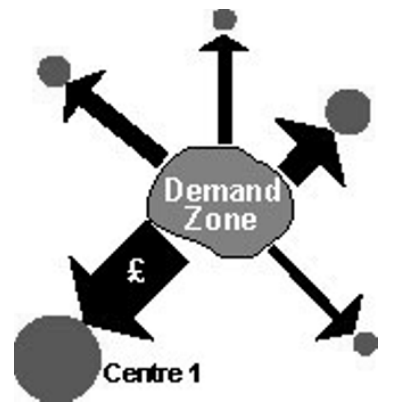

Outlet Sales

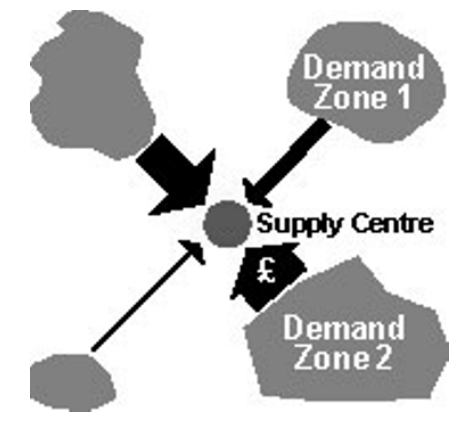

Market Share

Figure 2 Gravity model outputs

- a regression model can provide an estimate of potential for a new store but it does not provide any estimate of the impact that the new store will have on existing stores in the organisation's network;

- the historical data on which multiple regression models are built are usually biased towards the best performing sites as poorly performing sites have often been closed or are not developed. The result is that regression models nearly always underestimate the importance of location;

- regression models attempt to model complex relationships in a simple, linear fashion, which may lead to spurious results.

\section{Gravity models}

Gravity modelling, or spatial interaction modelling, is a technique which uses a mathematical model to predict the level of customer trips between residential zones and outlets or centres. The flow of customers is predicted based on the attractiveness of the destination (product offering, size and numbers of retailers) and ease of access (transport communications) by the consumer.

The technique is used by several of the UK's leading supermarket and high street retail chains for planning store networks and predicting revenues for new sites.

The growing popularity of gravity modelling owes much to the advantages the technique has over traditional statistically based models in that gravity models try to simulate the trip-making behaviour of consumers within the market and:

- the impact a new site or a closure has on existing stores, including those belonging to competitors;

- the effect on local market share of outlet openings and closures;

- the store's expected catchment area and the catchment overlap with other stores.

The answers to these questions are of major importance if the company is to avoid opening a profitable outlet which, due to impacts on existing outlets, results in a net loss to the company.

\section{SUMMARY}

The benefits of geographical analysis operate at many levels:

- managers can use the information in order to improve understanding of their markets and support strategic planning decisions of retail networks; - risks on investment decisions can be 
reduced significantly by employing robust and tested forecasting models;

- information concerning new sites can be assembled quickly and used to quickly filter out the poor locations in order to focus on the good locations;

- it can prove or disprove widely held business myths, such as, how far customers travel to visit an outlet and the type of people they are.

These are all useful benefits in themselves, but the acid test is the extent to which geographical analysis can be shown to lead to additional profit.
The difference between a successful and an unsuccessful outcome, in the majority of these decision-making areas, usually runs into millions of euros. In any year there are likely to be a number of such decisions. In contrast, the annual investment required to develop and support a profitable geographical analysis capability is a small fraction of these figures.

Provided that the capability can be implemented effectively, the decision to invest should not be a difficult one to make. The crucial consideration should not be one of cost, but one of value. 